High Explosive Spot Test Analyses of

Samples from Operable Unit (OU) 1111

Dexter McRae

Wallace Haywood

Jonathan Powell

Betty Harris 


\section{DISCLAIMER}

Portions of this document may be illegible in electronic image products. Images are produced from the best available original document. 


\section{CONTENTS}

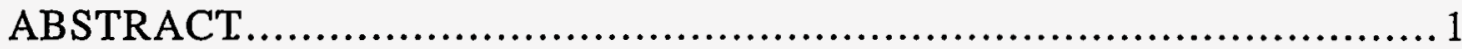

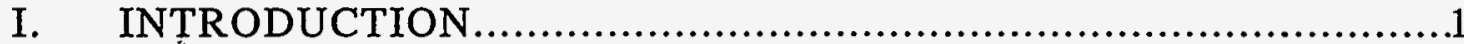

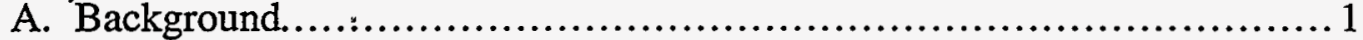

B. Areas Sampled and Purpose ............................................ 1

C. Possible Contaminants .................................................. 3

II. EXPERIMENTAL ......................................................

III. METHOD OF ANALYSIS ........................................... 5

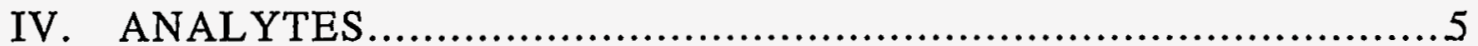

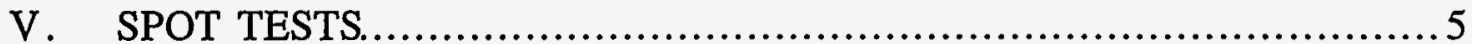

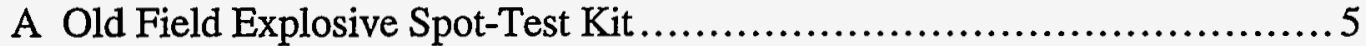

B. New Spot-Test Kit................................................. 5

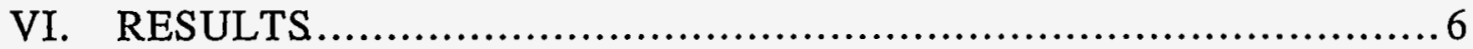

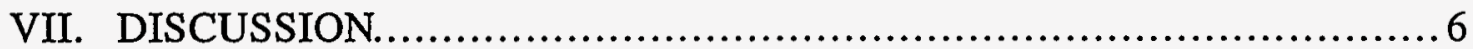

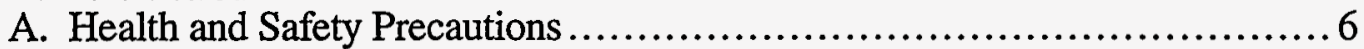

B. Results from Old Spot-Test Kit...................................... 6

C. Results from New Spot-Test Kit.......................................... 7

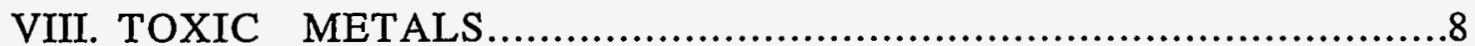

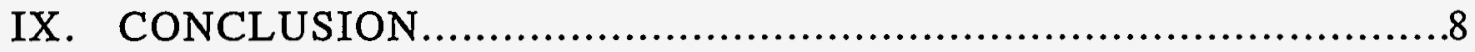

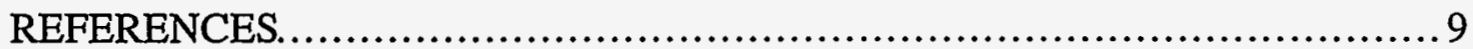




\title{
HIGH EXPLOSIVE SPOT TEST ANALYSES OF \\ SAMPLES FROM OPERABLE UNIT (OU) 1111
}

b y

Dexter McRae, Wallace Haywood, Jonathan Powell, and Betty Harris

\begin{abstract}
A preliminary evaluation has been completed of environmental contaminants at selected sites within the Group DX-10 (formally Group M-7) area. Soil samples taken from specific locations at this detonator facility were analyzed for harmful metals and screened for explosives. A sanitary outflow, a burn pit, a pentaerythritol tetranitrate (PETN) production outflow field, an active firing chamber, an inactive firing chamber, and a leach field were sampled. Energy dispersive X-ray fluorescence (EDXRF) was used to obtain semi-quantitative concentrations of metals in the soil. Two field spot-test kits for explosives were used to assess the presence of energetic materials in the soil and on items found at the areas tested. PETN is the major explosive in detonators manufactured and destroyed at Los Alamos. No measurable amounts of PETN or other explosives were detected in the soil, but items taken from the burn area and a high-energy explosive (HE)/chemical sump were contaminated. The concentrations of lead, mercury, and uranium are given.
\end{abstract}

\section{INTRODUCTION}

\section{A. Background}

Beginning in 1944 Technical Areas (TAs) mentioned in this report were involved in the experimental production and testing of explosives and in the production and destruction of detonators at Los Alamos. Several of the TAs became contaminated. Previous methods of detection and cleanup were not as accurate, and regulations were not as stringent as those we have today. Therefore, we are doing a semi-quantitative evaluation of selected areas in Operable Unit 1111 (OU 1111) (Map 1) to determine where explosives and toxic metals are found and the effectiveness of the field spot-test kits for explosives in detecting contaminants. Subsequently, contaminated areas will be remediated.

\section{B. Areas Sampled and Purpose}

On June 11, 1993, several soil samples and items from the Group DX-10 facilities at TAs-6, 7, 22, and 40 (See Maps 1 through 9) were collected by Betty Harris (Group DX-16), Cheryl Rofer (Group EES-1), and Laurence Creamer (Group DX-10). The purpose was to determine whether or not explosive contamination in soil and on items could be detected using the spot-test kits. Also determined was whether the metal contents of the soil: lead, mercury, and uranium 
were at a level hazardous to humans or to the environment. Samples and items were analyzed in the laboratory by Dexter McRae, Wallace Haywood, and Jonathan Powell.

A brief description and history of the areas sampled is given below: 1

TA-6-7 (Map 2), an inactive firing chamber completed January 1, 1946, is constructed of reinforced concrete and steel. The dimensions are $12 \mathrm{ft}$ long by $19 \mathrm{ft}$ wide by $12 \mathrm{ft}$ high. It was originally built as a laboratory, but used as a firing chamber for PETN detonator threshold testing from January 8, 1961, to December 27, 1965. It is now used as a chemical storage building.

TA-7 (Map 3), an inactive burn pit associated with Solid Waste Management Unit (SWMU) 7-001 $(\mathrm{a}, \mathrm{b})$, is approximately $12 \mathrm{ft}$ in diameter; it was used to destroy scrap detonators and for open detonation of explosives.

TA-22-1 (Map 4) is a laboratory/office building completed November 5, 1945. An outflow pipe associated with this building is the Potential Release Site (PRS). This was a detonator loading laboratory where explosives were pressed into caps. The explosives used were pentaerythritol tetranitrate (PETN); 1,3,5,7-tetrahydro-cycloocta-1,3,5,7-tetranitramine or cyclotetramethylene tetranitramine, octogen, (HMX, High Melting Explosive); 1,3,5-hexahydro-1,3,5-trinitrotriazine or cyclotrimethylenetrinitramine, hexagon, (RDX-Royal Demolition Explosive or Research and Development Explosive); 1,3,5-triamino-2,4,6-trinitrobenzene (TATB); and hexanitrostilbene (HNS).

TA-22-4 (Map 5) has been removed; an outflow pipe that extended from a hill near TA-22-1 was located in the vicinity of TA-22-4. Samples were taken near the pipe.

TA-22-25 (Map 6), initially a receiving building, constructed on November 21, 1949, is now empty but was used previously as a production bunker for PETN. The PRS is an industrial waste outflow (leach field) associated with the sump outside the bunker. PETN is the explosive of concern.

TA-22-34 (Map 7) is a chemical laboratory for explosive formulations built July 10, 1952 . The sump and septic outflow associated with this building is the PRS.

TA-22-42 (Map 8), a septic tank installed approximately June 1945, was made of reinforced concrete and measured $6-\mathrm{ft}$ long by 9 -ft in diameter by 5 - $\mathrm{ft}$ high. This structure was abandoned July 1952, and made inactive on July 29, 1955. It has a sanitary outfiow south of TA-22, and there is a concern for PETN contamination. 
TA-40-15 (Map 9) is an active firing site completed on February 6, 1950. It has been used extensively since that time, and there is a concern that RDX and 1,3,5-trinitrotoluene (TNT) contamination is present.

\section{Possible Contaminants}

The primary mission of Group DX-10, since the early 1940s, has been the manufacture and destruction of detonators produced at Los Alamos. Also, some experimental explosives and weapon components were test fired at this facility. Elevated metals concentrations, beryllium, lead, mercury, and uranium, in the soil as a result of these operation are a concern. PETN, RDX, HMX, HNS, and 1,3,5-N-trispicrylamino-1,3,5-s-triazine (PYX) are explosives commonly used and could be contaminants in the soil. The latter two, HNS and PYX, had limited application.

The amounts of ingredients in detonators are very small (milligrams quantities), but the number of detonators used and destroyed could have added significantly to the level of contamination.

PETN is the explosive common to most detonators. However, RDX, HMX, and PYX are also found in detonator cord. HNS was produced and used in one facility. Lead is the metal common to all detonators, and its concentration in the soil is increased significantly by the operations performed, past and present, in the Group DX-10 area.

Listed below is general information on the composition of common detonators, detonator cord, Detasheet, and squibs. This information was taken from "Energetic Material Users Hazard Information Index" and used as a guide to identify hazardous components of detonator and detonator products. 2

1. Detaflex Products (Detaprime Booster: UF-4, UF, UAL, UA-4, UA-6, EB-6m, EB-18, WG, GA, S; Detasheet, Detaflex; Ingredient: PETN/ Acetyltributyl Citrate/ nitrocellulose)

2. Detaline Cord (Non-Electric Initiation System; Ingredients: PETN/Acetyltributyl citrate)

3. Detaslide (Ingredients: PETN/Lead Azide/Red Lead Oxide/Silicon/Boron/Lead)

4. Detonating cord (Primacord; Primex; Ingredients: PETN/RDX/HMX/PYX)

5. Detonator, delay, electric, Du Pont (MS Delay Blasting Caps; Acudet Mark V Delay Electric Blasting Caps; Coal Mine Delay Electric Blasting Caps; Posidet; Trenchdet; Ingredients: PETN/Lead Azide/ Boron/Red Lead Oxide/Dibasic Lead Phosphite/Iron/Aluminum/ Zinc/Bronze/Lead/Silicon/Graphite) 
6. Detonator, delay, in-hole: dh-1, detaline (Ingredients: PETN/Lead Azide/Red Lead Oxide/Silicon/Boron/Lead)

7. Detonator, electric (Du Pont Specialty "E" Products; Electric Blasting Caps; Ingredients: Lead Styphnate/HNS/Lead Dinitroorthocresylate/TACOT/Boron/Ferric Oxide/Magnesium/ Potassium Chlorate/ Smokeless Powder/ RDX, Cyclotrimethylenetrinitramine/ Iron /Copper/Tellurium Dioxide)

8. Detonator, electric (Du Pont Specialty "S" Products; Squibs; Ingredients: Lead Dinitroorthocresylate/Potassium Perchlorate/Barium Peroxide/Smokeless Powder/ Black Powder/Dibasic Lead Phosphite/Boron/Magnesium/Selenium/Aluminum/Commercial Bronze)

9. Detonator, Mild, Electric and Non-Electric ("DFP" PRODUCTS) (Ingredients: Lead Azide/PETN/RDX/Lead Dinitroorthocresylate/ Potassium Chlorate/Selenium/Smokeless Powder/Aluminum/Copper/Lead)

10. Detonator, non-electric (Du Pont Specialty "C" Products; Ingredients: PETN/RDX/HNS/Lead Azide/Lead Styphnate/Aluminum/ Commercial Bronze)

11. Detonator, non-electric (Primadet; Ingredients: PETN/Lead Azide/Silicon/Red Lead/ Barium Chromate/ Potassium Perchlorate/ Ottawa Silica/Lead Chromate/ Selenium/ Molybdenum/Tungsten/Aluminum/Lead)

12. Standard black powder (Fuse; Ingredients: Potassium Nitrate/ Charcoal/Sulfur-Sodium Nitrate can be substituted for Potassium Nitrate in this composition, but the proportions are changed somewhat.)

A list of detonators taken from Group ESA-2 (formally WX-3), per SOP 1.1.0 is given in Table VII.

\section{EXPERIMENTAL}

The soil analysis for toxic metals was done in collaboration with Ken Griechen (Group ESA2). Ken used Energy Dispersive X-ray Fluorescence (EDXRF) analysis to obtain semi-quantitative data and ppm concentrations for metals in the soil.

Samples were collected in the field, taken to the laboratory, and tested using Reagent A, Reagent $B$, and Reagent $C$ from the old explosive spot-test kit and all three reagents from the new spot-test kit. We tested HNS and PYX for the first time. These compounds have structural components similar to both TNT and TATB. 


\section{METHOD OF ANALYSIS}

We analyzed soil and items from several areas. Milligram quantities of the soil were scooped from the container and placed on clean white filter paper, then few drops of the test reagent were added. A white ceramic spot plate may also be used. In theory, if the soil is contaminated, a color develops within seconds that is characteristic of the given group of explosives. The color from the use of Reagent B of the old spot-test kit is enhanced by shining a short-wave ultraviolet (UV) light on the spot. 3

\section{ANALYTES}

We used the field spot-test kits to screen for TNT RDX, HMX, PETN, HNS, and PYX (Figure 1). We analyzed samples for lead, uranium, mercury, and nickel using EDXRF.

\section{SPOT TESTS}

A. Old Field Explosive Spot-Test Kit The old spot-test kit consists of three reagents known as the following:

Reagent A - [An 80\%/20\% mixture of the solvents $\mathrm{N}, \mathrm{N}$-dimethylformamide (DMF) and di-N-butylamine] is used to test for TNT and for explosives similar in structure to TNT, such as trinitroaromatic derivatives or nitroaromatic amines.

Reagent B - [tetra-N-butylammonium hydroxide in methanol with a fluorescent dye dissolved in dimethylsulfoxide (DMSO) $2 \% / 98 \mathrm{wt} \%$, as an indicator shows a characteristic color for RDX, HMX, and PETN. A short wavelength, ultraviolet light is used to enhance the color produced in this test.

Reagent C - (potassium hydroxide, water, DMSO, 5/5/90 wt $\%$ is used to test for TATB), produces an orange color, but gives a distinct color test different from that of TATB for tetryl, PYX, or HNS (red) and TNT (purple to black). 4

B. New Spot-Test Kit The new field explosives spot-test kit consists of Reagent $\mathrm{C}$ from the old kit, but more concentrated, now called Solution 1, Hydrochloric acid, sulfanilide-Solution 2, and N-Naphthalenediamine dihydrochloride-Solution 3. 


\section{RESULTS}

Results from the evaluation of the Group DX-10 facilities described previously, Maps 1 through 9, are given in Tables I-VI. Most of this facility is not contaminated, but the surfaces of items taken from the area tested positive for PETN.

Positive tests were dark purple or reddish brown and very strong colors. Also, where items testing positive were found, we should have gotten positive tests with all three solutions from the new spot-test kit; this was not the case. Results from the spot-test analyses are given in Tables I and II, metals are shown in Tables III and IV, and pH in Table VI. Characteristic colors were obtained for HNS and PYX, using all reagents from both kits (Table V). These results were not surprising, but should be noted in the spot-test kits.

\section{DISCUSSION}

\section{A. Health and Safety Precautions}

We have determined from historical data that the concentrations of explosives absorbed or dissolved in the soil are not high enough to cause a safety hazard from possible explosion or detonation. However, caution was taken in cases where chunks or pieces of explosives were found on the surface or at subsurface level. Health problems and environmental concerns caused by the toxic metals and explosives are possible.

Toxic metals and explosives are rarely life threatening when bound to the soil. But they could be carcinogens, teratogens (reproductive toxins), and/or mutagens if ingested or absorbed through the skin in large enough quantities. Dust and soil were both handled with care. Dust masks were worn in the laboratory to prevent ingestion. The solvents used to dissolve the material were not inhaled, and protective clothing was worn to prevent chemicals from coming in contact with eyes and skin. The solutions, when possible, were used under a hood.

\section{B. Results from Old Spot-Test Kit}

Reagent A will detect milligram quantities of raw explosives and explosives in the soil. To get results, enough of the explosive must come in contact with the filter paper, or enough must be dissolved out when the reagent is added to the sample. Other media do not appear to interfere with these results. A purple-to-black color is produced if TNT or its analogs are present. No TNT or similar explosives (nitrotoluenes) were found in the areas tested. John Baytos determined $100 \mathrm{ppm}$ in soil as the detection level for TNT. 3 
The orange material from the wall of TA-6-7 remained orange, which means that the color was not produced by the reagent.

Reagent $\mathrm{B}$ gives a bright yellow color on the filter paper if no contamination is present. If RDX, HMX, or PETN is in the soil, a blue-black color is produced. This color is enhanced when a short-wave UV light is used to illuminate the spot. Positive tests were found at the outflow pipe from the Laboratory/Office building, TA-22-1 and at the sump/septic outflow from the Chemical Laboratory for HE formulations. Also, positive tests were found on all articles, except glass, from the firing chamber (TA-40-15) and from the burn pit at TA-7. The different media did not interfere with the results of the test. It should be noted that "all three reagents" from the new spot-test kit should also have given a positive test for these items. This kit is designed to test for as low as a $100 \mathrm{ppm}$ of HMX, RDX, or PETN.

Reagent $\mathrm{C}$ was designed to test for TATB (gives an orange color); also it gives a red color specific to tetryl, HNS, PYX and a purple color unique to TNT. Therefore, Reagent $\mathrm{C}$ can be used to detect these compounds. Reagent $C$ gave negative results for the soil samples and items tested. Therefore, one would conclude that neither TNT, tetryl, PYX, HNS, nor TATB was found at the sites tested. Again, $100 \mathrm{ppm}$ was the detection limit cited in the literature.

HNS and PYX were tested for the first time with the spot-test kits, and both gave characteristic colors with Reagents A, B, and C, and the three solutions from the new kit (Table V). Therefore, the use of the kits can be expanded to include HNS and PYX. The color intensity for all materials is concentration dependent.

\section{Results from New Spot-Test Kit}

All three reagents were used, first separately then together. Only the rust from the wall at TA6-7 was a concern, because it was orange, and remained orange during the test. Otherwise, no contamination was indicated from the use of the new spot-test kit. It should be noted that the new kit is still being developed.

The first solution in the new kit is the same as Reagent $\mathrm{C}$ in the old kit, but more concentrated. The base is used to hydrolyze the explosive, causing a colored product to be formed. The second solution, $\mathrm{HCl}$, in the new kit neutralizes the sodium hydroxide from the first reagent and in the process nitrous acid is formed. The latter diazotizes the aromatic-amines portion of the explosive. The third solution forms an azo dye, a highly colored compound, with this diazonium salt produced form Solution 2. 
When all three solutions are used (as one reagent) in the new kit, a purple color is obtained for explosives. It does not detect ammonium nitrate or nitrate salts and gives a negative test for nitroguanidine. This combined reagent should detect PETN and other basic explosives. However, we did not get positive results on any of the items. There may be interference from the media on which the contamination is found.

A word of caution is given because in other areas, such as TA-12, we could not detect contamination using the field explosive spot-test kit even though the area was contaminated with small pieces and chunks of explosives on the ground. Solubility, degradation, and concentration will play a major part in results from the spot-test kits, and incorrect conclusions can be drawn if this is the only indicator tool used.

\section{TOXIC METALS}

The results from the semi-quantitative analyses of the metals show that metals concentrations are not a concern. One should keep in mind that this is a semi-quantitative method, and should not be the only test used.

\section{CONCLUSIONS}

The spot-test kit is a very useful tool, but it cannot be used reliably to "swipe" the soil and confirm with confidence the presence or absence of explosives. When one scoops the soil and drops the reagent directly into the sample, better results are obtained. Both kits work best on surfaces and with highly contaminated soil where there are explosives dissolved in the matrix. 


\section{REFERENCES}

1. Fischer, Edward A., Group ENG-7, Los Alamos National Laboratory Engineering Record, Los Alamos, New Mexico, July 1993.

2. Hooker, L. Z., Ingersoll, D., Prigg, C. J., Runkle, B. K. "Compilation of Hazard Information," Sandia National Laboratory Report UC-607, Vol. 1, Index, February 1991.

3. Baytos, John, "Field Spot-Test Kit for Explosives," Los Alamos National Laboratory Report LA-12071-MS, July 1991.

4. Harris, B. W. "TATB, Strong Basic Reactions Provide Soluble Derivatives for Simple Qualitative High Explosive Spot Test," J. Energetic Mater., Vol. 3, p. 14 (1985). 


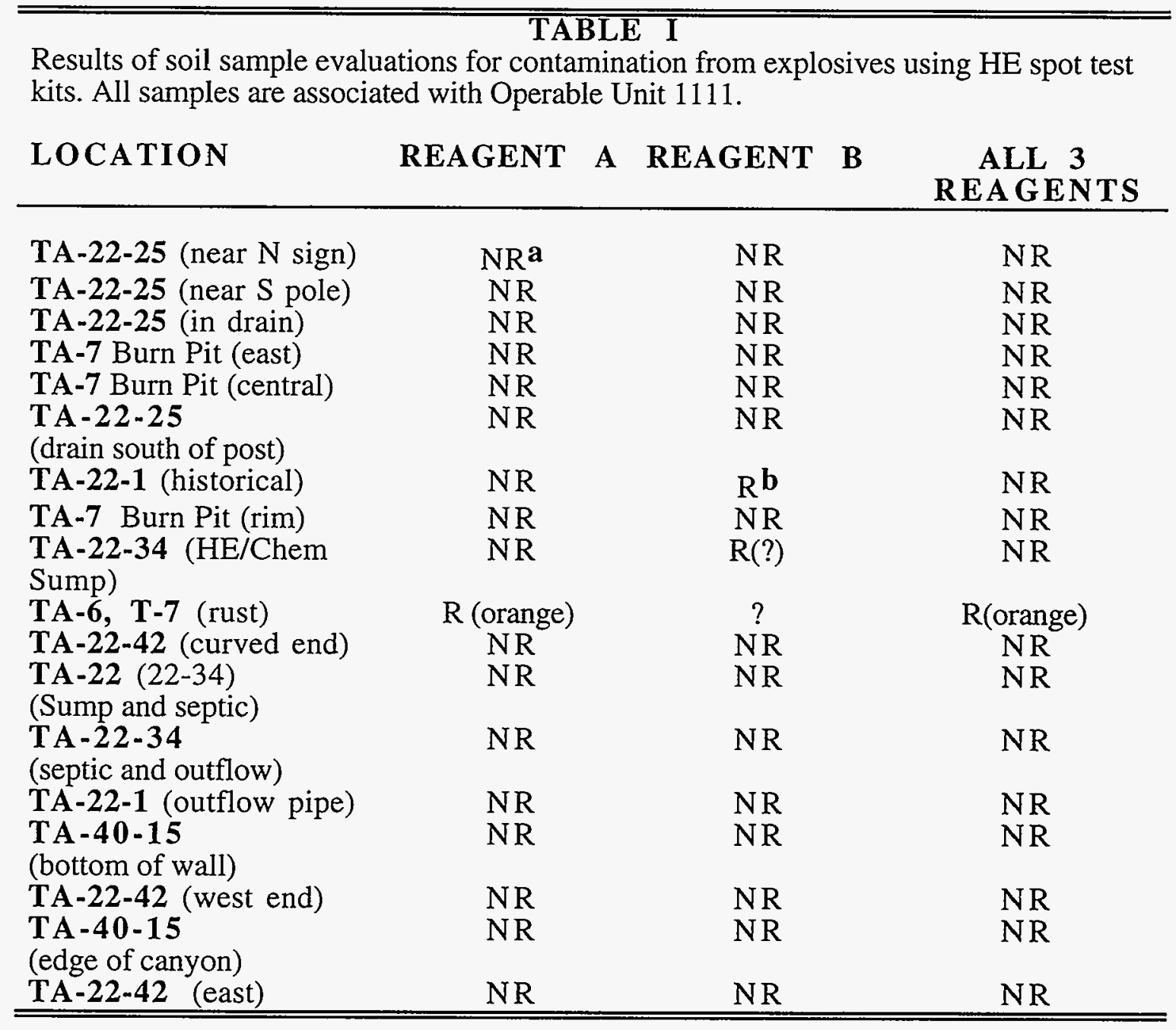

aNR $=$ no reaction.

$\mathbf{b}_{\mathrm{R}}=$ a positive reaction. 
Items taken from the test sites, burn pit, and drain field associated with Operable Unit 1111 were tested using the field spot-test kits for explosives.

\begin{tabular}{|c|c|c|c|c|}
\hline ITEMS & $\begin{array}{c}\text { REAGENT } \\
\mathbf{A} \\
\end{array}$ & $\underset{B}{\text { REA GENT }}$ & $\underset{C}{\text { REA GENT }}$ & $\begin{array}{c}\text { ALL } 3 \\
\text { SOLUTIONS } \\
\end{array}$ \\
\hline TA-40-15 (plastic) & $\mathrm{NR}^{\mathbf{a}}$ & $\mathbf{R} \mathbf{b}$ & NR & NR \\
\hline TA-40-15 (glass) & NR & NR & NR & NR \\
\hline $\begin{array}{l}\text { TA-40-15 (wall) } \\
\text { TA-7-burn nit (center) }\end{array}$ & NR & NR & NR & NR \\
\hline metal bar & NR & NR & NR & NR \\
\hline soil & NR & $\mathbf{R}$ & NR & NR \\
\hline glass & NR & $\mathbf{R}$ & NR & $\mathrm{NR}$ \\
\hline metal & NR & $\mathbf{R}$ & NR & $\mathrm{NR}$ \\
\hline rock & NR & $\mathbf{R}$ & NR & NR \\
\hline $\begin{array}{l}\text { TA-7 [not part of } \\
\text { SWMU 7001(b)] }\end{array}$ & & & & \\
\hline soil & NR & $\mathbf{R}$ & NR & NR \\
\hline rusty nail & NR & $\mathbf{R}$ & NR & NR \\
\hline metal part & NR & $\mathbf{R}$ & NR & NR \\
\hline rubber & NR & $\mathbf{R}$ & NR & NR \\
\hline glass & NR & $\mathbf{R}$ & NR & NR \\
\hline gold part & NR & $\mathbf{R}$ & NR & NR \\
\hline rusty part & NR & $\mathbf{R}$ & NR & NR \\
\hline rock-like & NR & $\mathrm{R}$ & NR & NR \\
\hline TA-22-25 spongy rock & NR & NR & NR & NR \\
\hline
\end{tabular}

a $\mathrm{NR}=$ no reaction

$\mathbf{b}_{\mathrm{R}}=$ a positive reaction

Energy dispersive X-ray fluorescence (EDXRF) analyses of standard when run as an unknown as proof of process. Standard concentration (ppm) and the amounts detected are listed.

ELEMENT Conc. in STD Amt. Detected Deviation

\begin{tabular}{rrrr}
$\mathrm{Ni}$ & 31 & 11.4 & 18.6 \\
$\mathrm{Hg}$ & 0 & 1.4 & 1.4 \\
$\mathrm{~Pb}$ & 91 & 72.0 & 19.0 \\
$\mathrm{U}$ & 31 & 22.1 & 8.9 \\
\hline
\end{tabular}




\begin{tabular}{lcccc}
\hline \hline & \multicolumn{5}{c}{ TABLE } & \multicolumn{1}{l}{ IV } & & \\
Concentrations in PPMs of metals found in the soil taken from OU & 111. \\
SAMPLE & Ni & H g & Pb & U \\
\hline $\begin{array}{l}\text { TA-40-15 } \\
\text { bottom of wall }\end{array}$ & 40.0 & N D & ND & 7.1 \\
$\begin{array}{l}\text { TA-7 Burn Pit } \\
\text { center }\end{array}$ & 8.6 & $>1.0$ & 12.5 & 2.9 \\
$\begin{array}{l}\text { TA-22-1 } \\
\text { Leach Field }\end{array}$ & 10.4 & ND & 9.3 & 3.9 \\
$\begin{array}{l}\text { TA-22-4 } \\
\begin{array}{l}\text { Outflow pipe } \\
\text { TA-22-25 }\end{array}\end{array}$ & 16.3 & $>1.0$ & 10.1 & ND \\
$\begin{array}{l}\text { PETN Prod. Bunker } \\
\text { TA-22-34 }\end{array}$ & NDa & ND & ND & 15.7 \\
$\begin{array}{l}\text { Septic/HE Sump } \\
\text { TA-22-42 } \\
\text { Leach Field }\end{array}$ & ND & ND & 4.8 & ND \\
\hline \hline
\end{tabular}

aND $=$ not detected

\section{TABLE V}

Results of the spot test for hexanitrostilbene (HNS) and N-tripicrylamino-1,3,5-triazine (PYX).

\begin{tabular}{lccc} 
REA GENT & PYX & HNS & $\begin{array}{l}\text { HNS/Kel-F } \\
\mathbf{8 0 0}\end{array}$ \\
\hline Reagent A & dk reda & dk purple & dk purple \\
Reagent B & dk orange & dk orange & blue-black \\
Reagent C & orange red & dk purple & dk red \\
Solution 1 & dk red & dk red & dk red \\
Solution 3 & yellow & Lt yellowb & Lt purple \\
Solution 2 & yellow & yellow brown & Lt yellow \\
\hline \hline
\end{tabular}

\footnotetext{
$\mathbf{a}_{\mathrm{dk}}=\mathrm{dark}$

$\mathbf{b}_{\mathrm{Lt}}=$ light
} 


\section{TABLE VI}

$\mathrm{pH}$ results for soil samples taken from Operable Unit 1111.

\begin{tabular}{llc} 
SAMPLE & & pH \\
\hline TA-22-34 & Septic outflow & $6.0-6.4$ \\
TA-22-34 & HE/Chem sump & $6.0-6.4$ \\
TA-40-15 & Bottom of wall & $6.0-6.4$ \\
TA-22-1 & Historical & $6.0-6.4$ \\
TA-22-1 & Leach Field wall & $6.0-6.4$ \\
TA-22-1 & Outflow pipe & $6.0-6.4$ \\
TA-7 & SWMU 7-0016 & $6.0-6.4$ \\
TA-22-42 & Leach Field curve end & $6.0-6.4$ \\
\hline \hline
\end{tabular}

\section{TABLE VII}

\section{APPROVED DETONATORS FROM ESA-2 SOP 1.1.0}

\section{A. High-energy exploding bridgewire (EBW) detonators}

The following EBW detonators have been approved for assembly into test devices:

$\begin{array}{llll}\text { 1E23 } & \text { ER-213 } & \text { MC1991 } & \text { SE1 } \\ \text { 1E26 } & \text { ER-235 } & \text { MC2370 } & \text { SE1/31 } \\ \text { 1E26B } & \text { ER-302 } & \text { MC2427 } & \text { RP1 } \\ \text { 1E27 } & \text { ER-312 } & \text { MC2990 } & \text { RP2 } \\ \text { 1E29 } & \text { ER-344 } & \text { MC3041 } & \text { RP80 } \\ \text { 1E30 } & \text { ER-350 } & \text { MC3343 } & \text { RP84 } \\ \text { 1E31 } & & \text { MC3348 } & \text { RP87 } \\ \text { 1E33 } & & \text { MC3355 } & \\ \text { 1E34 } & & \text { MC3366 } & \\ \text { 1E35 } & & & \\ \text { 1E36 } & & & \\ \text { 1E37 } & & \text { MK22A (UK) } \\ \text { 1E38 T.F. } & & \text { MK13C (UK) } \\ \text { 1E } & & & \end{array}$

B. The following low-energy detonators have been approved for assembly into test devices:

\begin{tabular}{ll} 
MC2987 & 3E1 \\
MC3196 & 3E1A \\
MC3332 & 3E1B \\
MC3423 & 3E1D \\
& 5E1 \\
\hline \hline
\end{tabular}




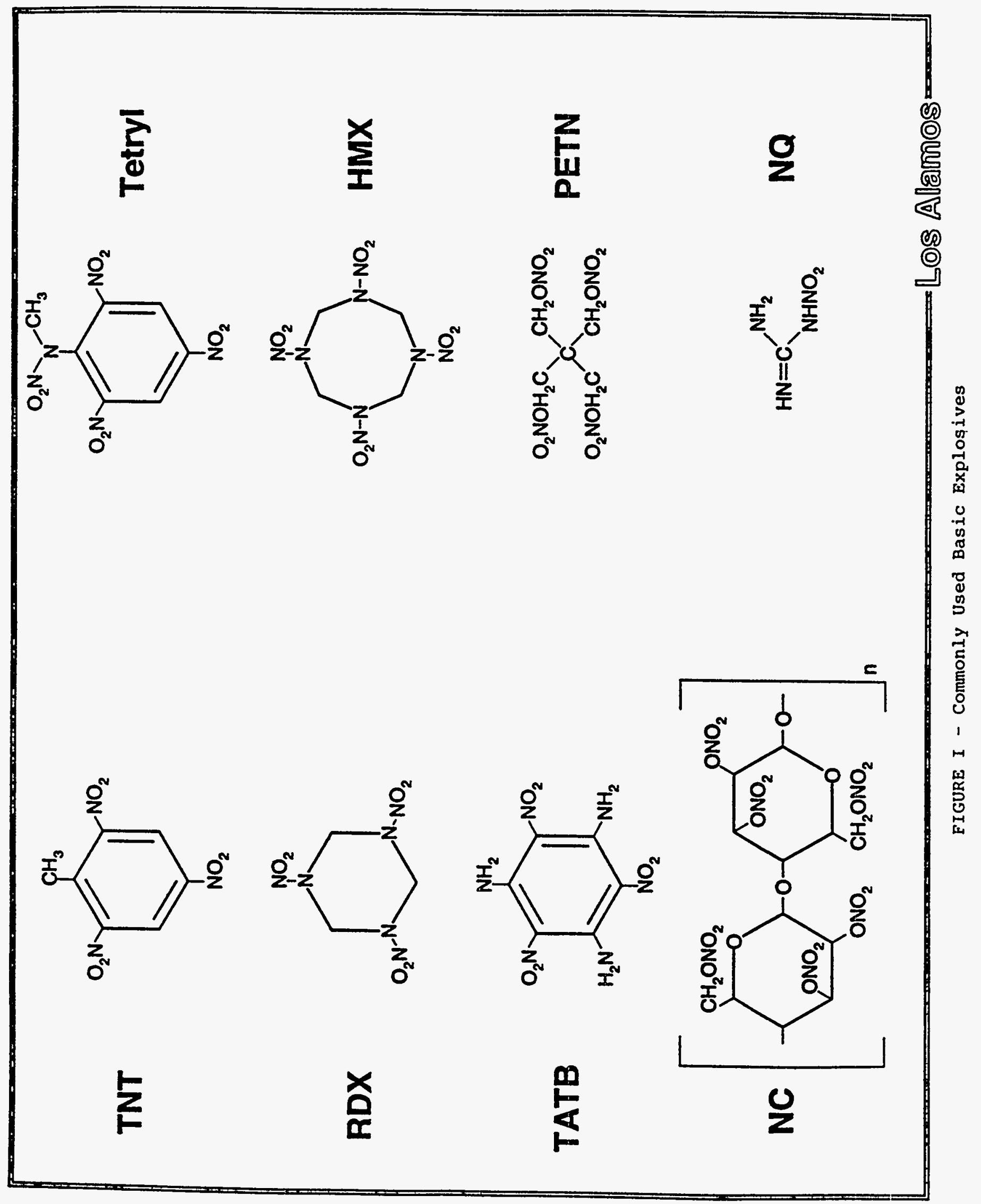




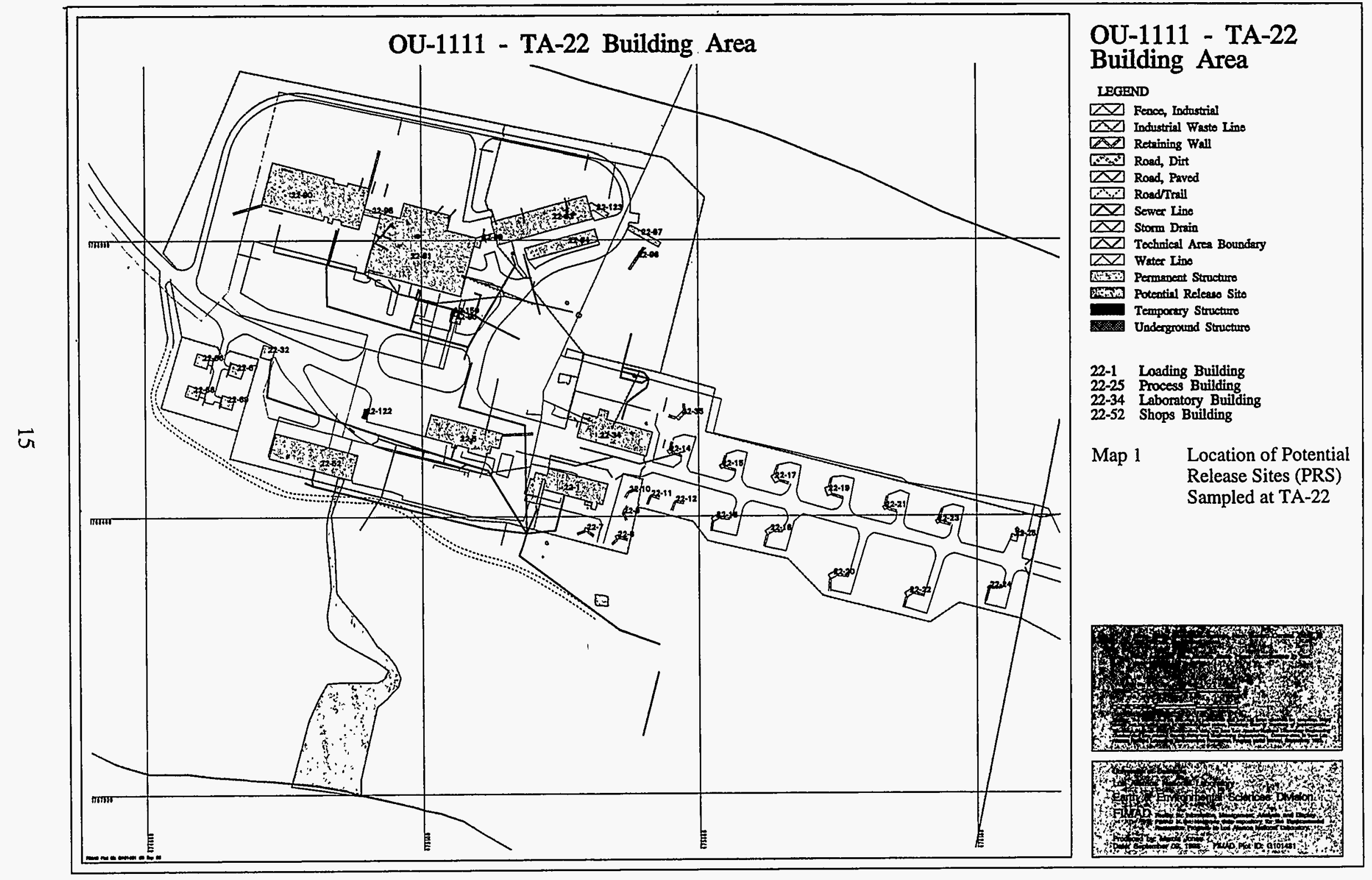




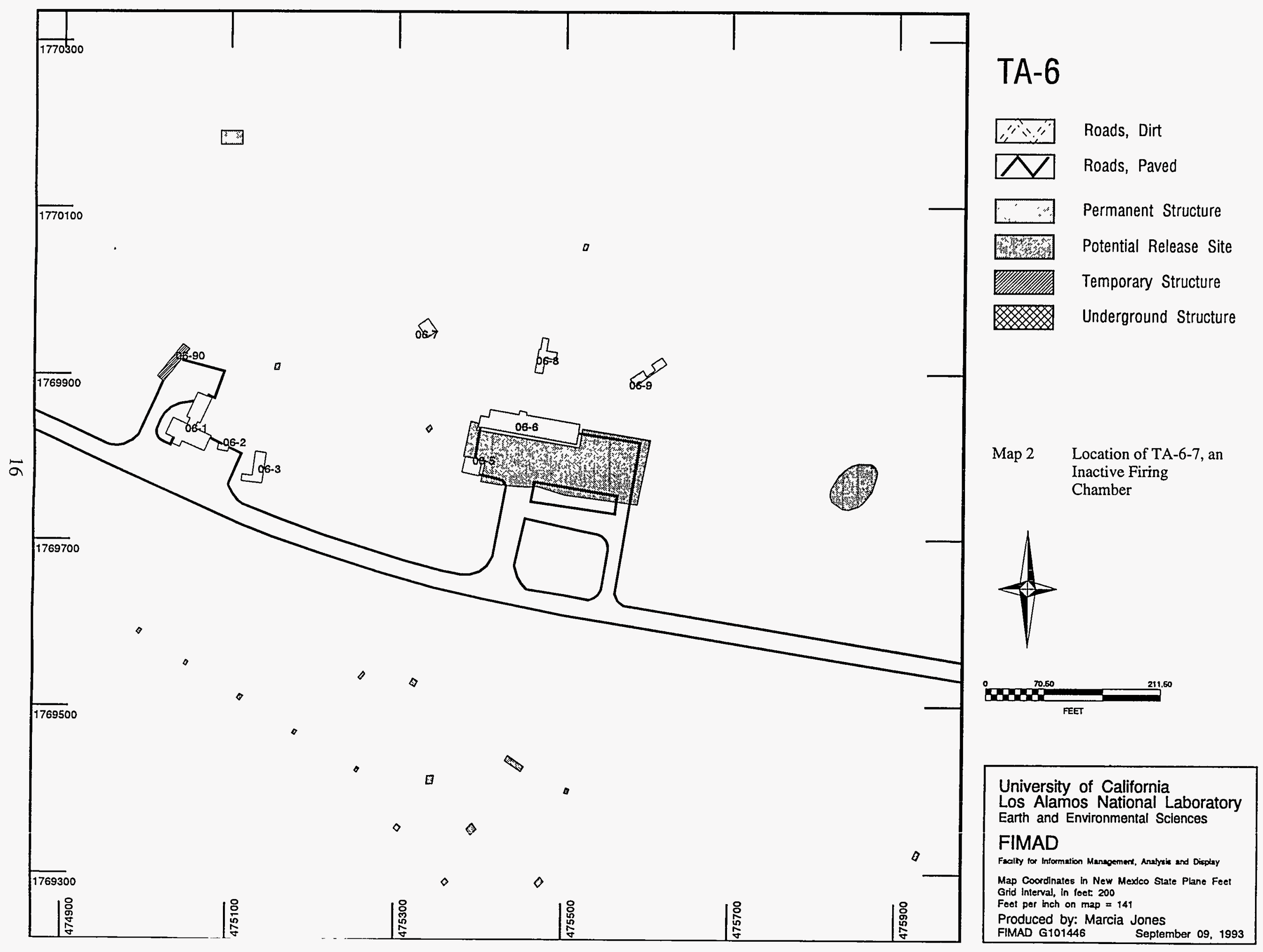




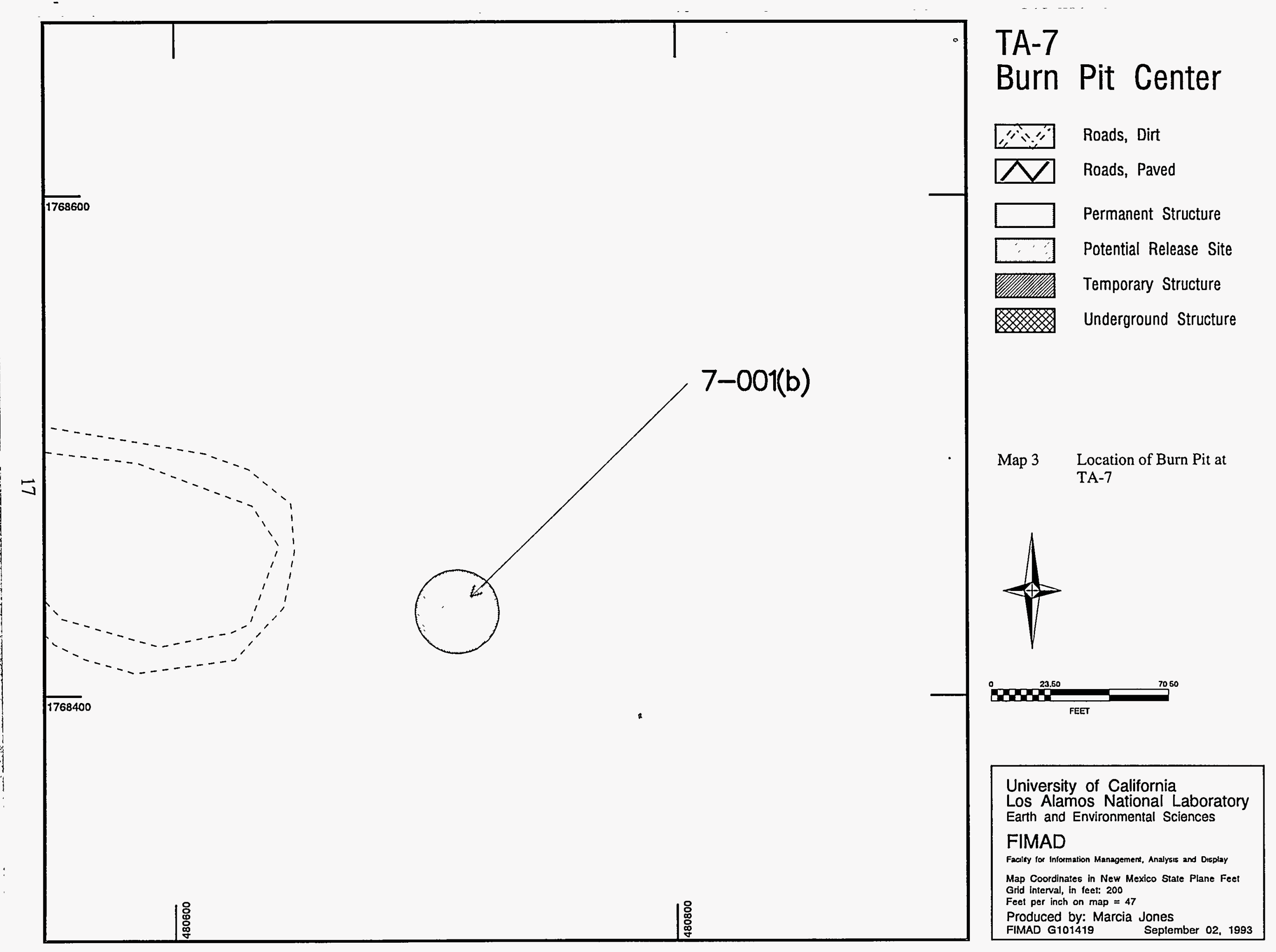




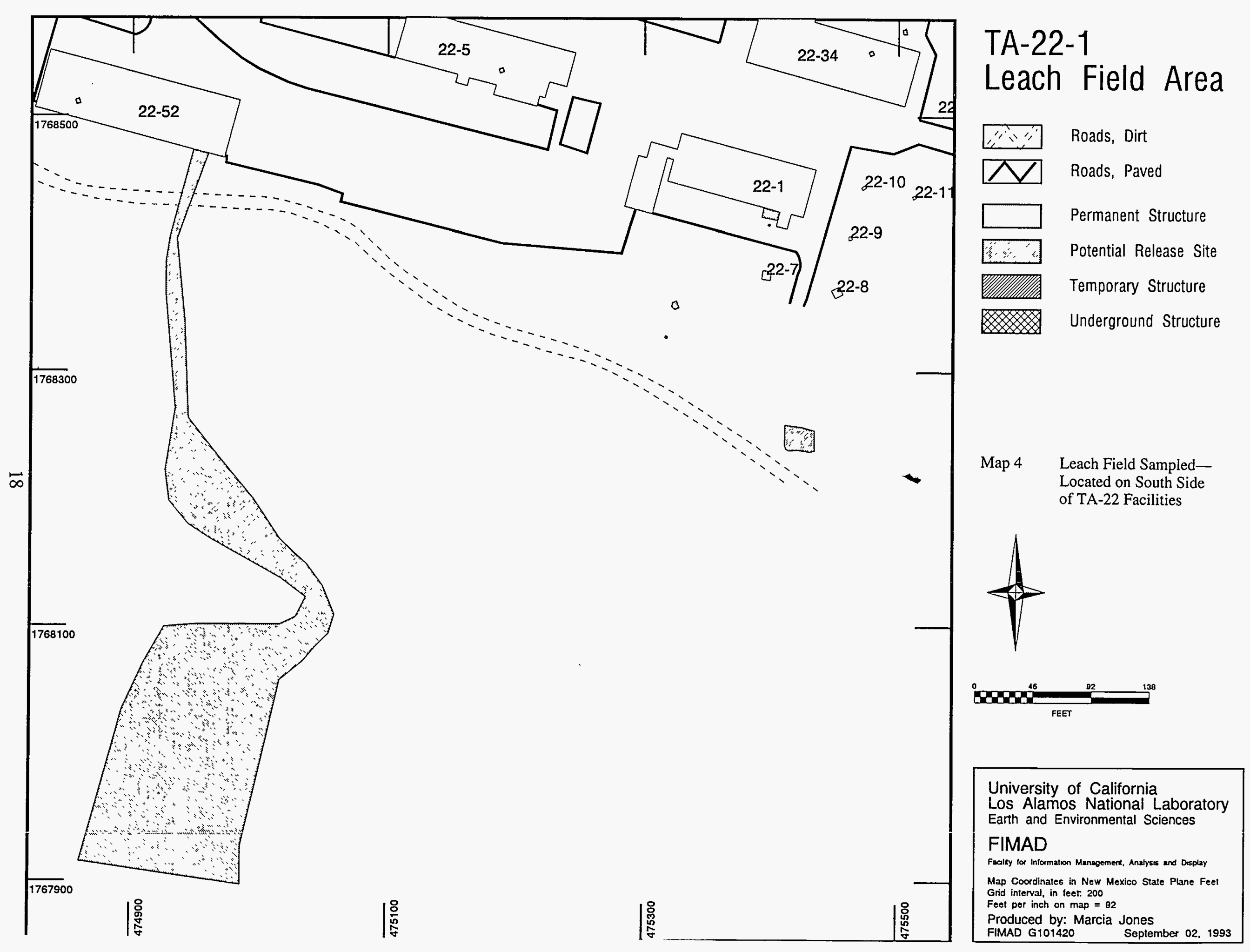




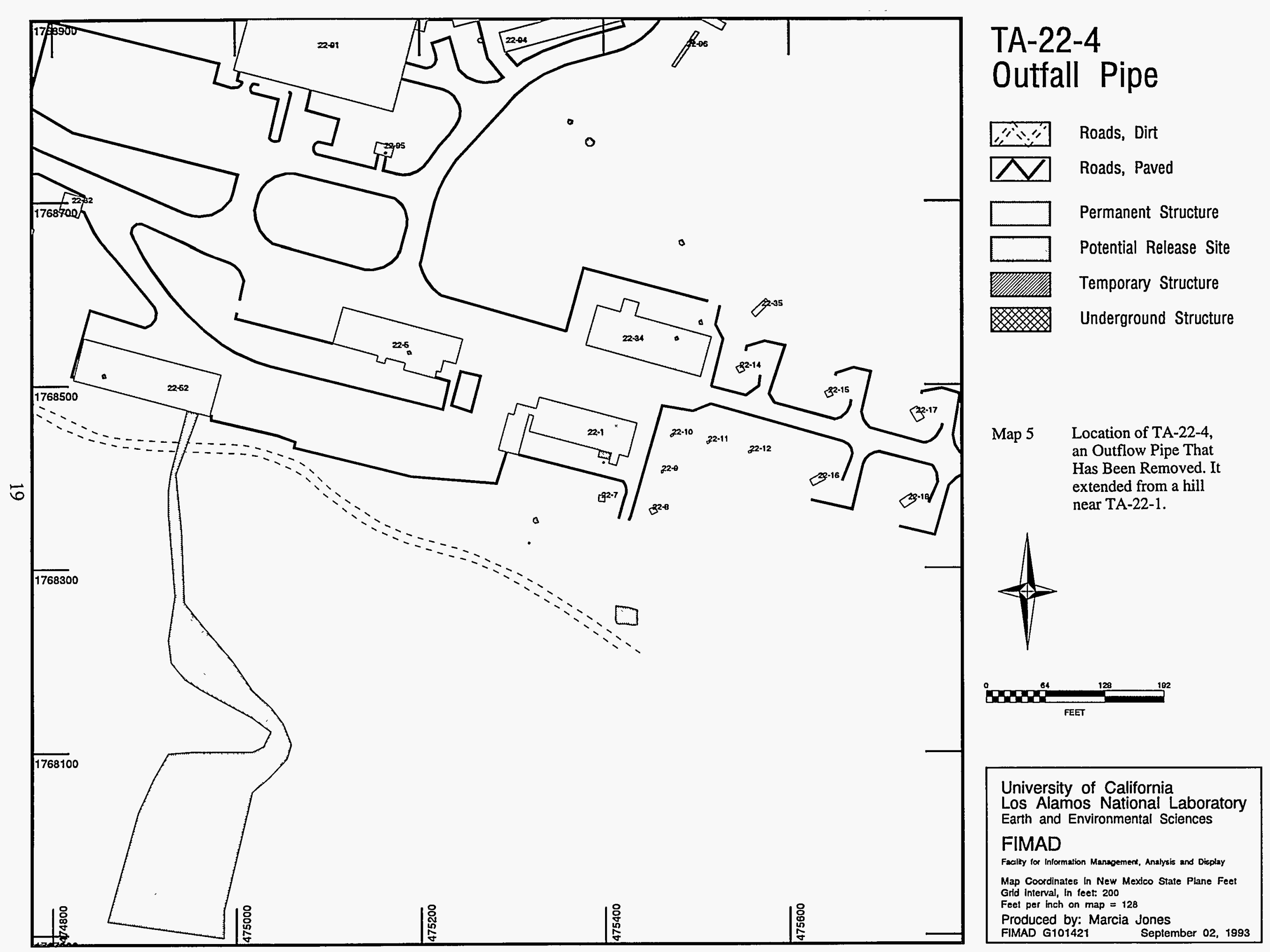




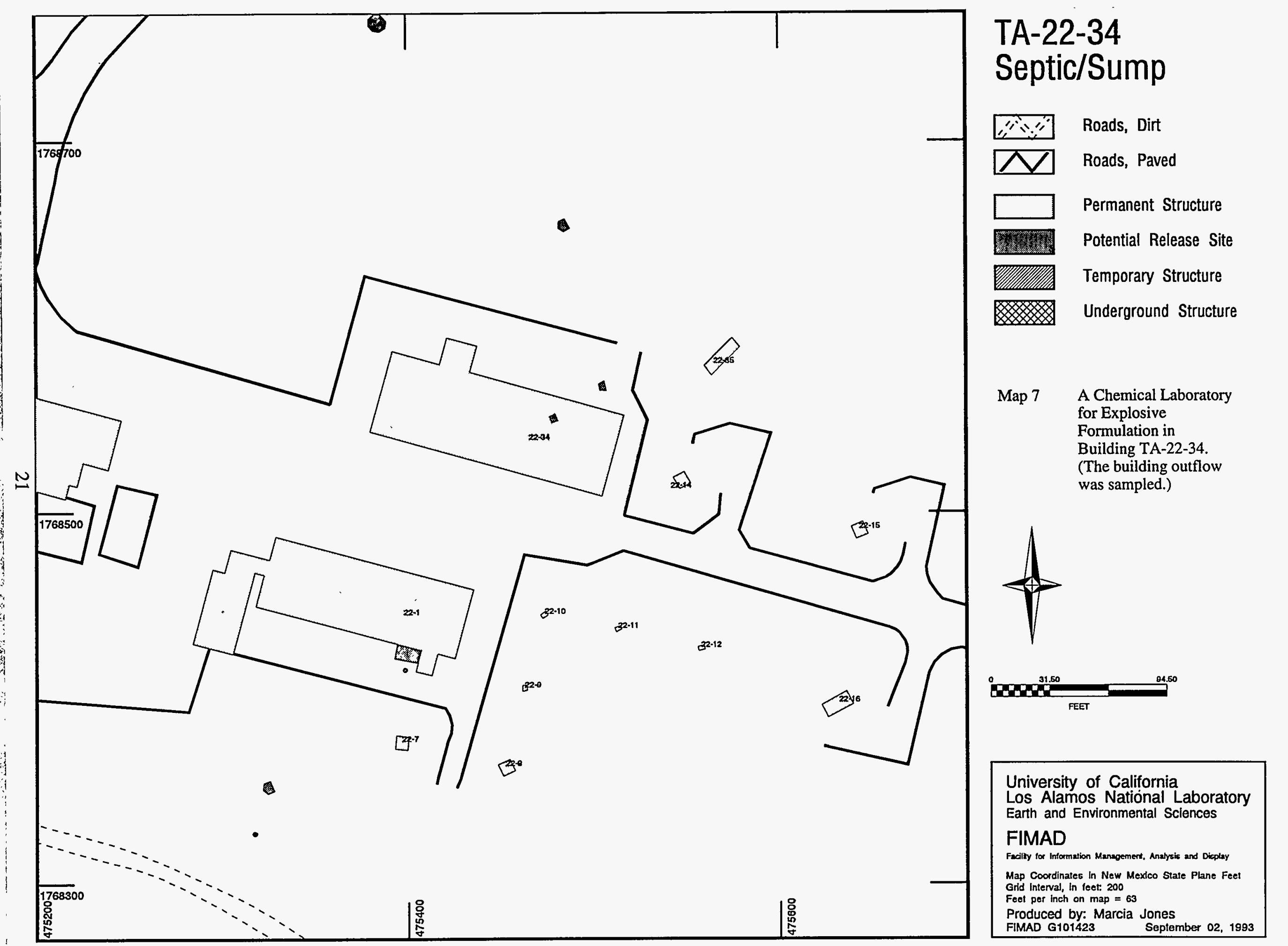




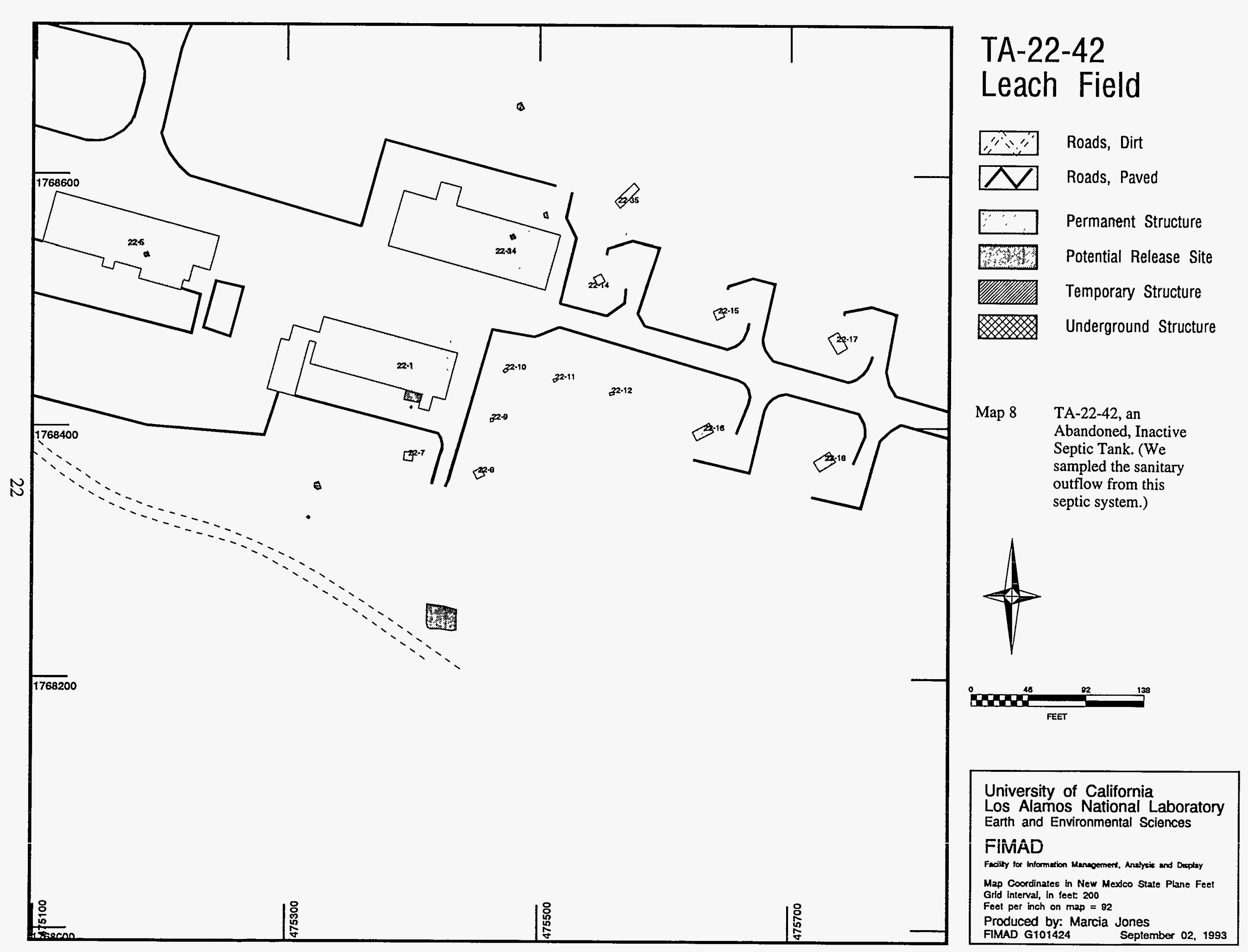


